\title{
Frequency and clinical relevance of EGFR mutations and EML4-ALK translocations in octogenarians with non-small cell lung cancer
}

\author{
Amanda Tufman ${ }^{1,2}$ \\ Kathrin Kahnert ${ }^{1,2}$ \\ Thomas Duell ${ }^{2,3}$ \\ Diego Kauffmann- \\ Guerrero ${ }^{1,2}$ \\ Katrin Milger ${ }^{1,2}$ \\ Christian Schneider ${ }^{2,4}$ \\ Julia Stump ${ }^{1,2}$ \\ Zulfiya Syunyaeva ${ }^{1,2}$ \\ Rudolf Maria Huber ${ }^{1,2}$ \\ Simone $\operatorname{Reu}^{2,5}$ \\ 'Division of Respiratory Medicine \\ and Thoracic Oncology, Department \\ of Internal Medicine V, Thoracic \\ Oncology Centre Munich, Ludwig- \\ Maximilians University, ${ }^{2}$ German \\ Center for Lung Research, \\ Comprehensive Pneumology \\ Center (DZL CPC-M), ${ }^{3}$ Asklepios \\ Pulmonary Hospital in Munich- \\ Gauting, ${ }^{4}$ Department of Thoracic \\ Surgery, ${ }^{5}$ Pathology Institute, \\ Ludwig-Maximilians University, \\ Munich, Germany
}

This article was published in the following Dove Press journal:

OncoTargets and Therapy

25 October 2017

Number of times this article has been viewed

Background: Tyrosine kinase inhibitors (TKIs) have improved response rates in some patients with non-small cell lung cancer (NSCLC), and testing for EGFR mutation and ALK translocation is recommended for all patients with advanced lung adenocarcinoma. The frequency of driver mutations in elderly and very elderly patients has not been described.

Patients and methods: We reviewed EGFR and ALK in patients over the age of 70 years diagnosed and treated at our center in 2015 (subgroups: 70-74, 75-79 and >80 years). We then assessed a second cohort, including all patients with lung cancer over the age of 80 years diagnosed in 2014. We also analyzed smoking history, treatment and response.

Results: In the 2015 cohort of 179 patients, 16 were 80 years or older at diagnosis. Six of eight (75\%) octogenarians with non-squamous NSCLC were EGFR or ALK positive. The 2014 cohort confirmed the high rate of driver alterations in octogenarians. Of 334 patients, 32 were 80 years or older and, of these, 10 had non-squamous histology and were tested for driver alterations (four of 10 [40\%] EGFR or ALK positive). Rates of genetic drivers were somewhat lower in patients with non-squamous NSCLC aged 70-74 years (27.0\%) and 75-79 years (26.7\%). When treated with a TKI, octogenarians had high response rates and progression-free survival. Most octogenarians with lung adenocarcinoma were never smokers, with an inverse correlation of pack-years smoked to age at diagnosis.

Conclusion: Very elderly patients with non-squamous NSCLC show high rates of driver alterations in EGFR and ALK. This, often frail and comorbid, population may not be fit for treatment with cytotoxic chemotherapy and may benefit from targeted treatments. Testing for EGFR and ALK alterations should not be restricted to younger patients. The biology of lung cancer in the very elderly may differ from that of moderately elderly patients, as longevity may select for individuals more resistant to, or with little exposure to, environmental carcinogens.

Keywords: molecular biology, pathology, elderly, very elderly, NSCLC, biomarker, targeted therapy

\section{Introduction}

Tyrosine kinase inhibitors (TKIs) targeting EGFR mutations and EML4-ALK translocations improve response rates and prolong survival in a subset of patients with advanced non-small cell lung cancer (NSCLC). Previous studies have linked EGFR mutation to younger age, female gender and a never or light smoking history. ${ }^{10,28,29}$ ALK translocation has also been shown to occur in younger patients and those with a little exposure to cigarette smoke. As a result, patients included in trials of targeted TKIs have often been relatively young, with an average age of 61 years in the Lux Lung 3 trial $^{1}$ and 53 years in the Profile 1014 trial. $^{2}$ Some trials of EGFR TKIs excluded
Correspondence: Amanda Tufman Thoracic Oncology, Department of Internal Medicine V, Ludwig-Maximilians University, Ziemssenstraße I, Munich 80336, Germany

Tel +49894400 52590

Fax +4989440054905

Email amanda.tufman@med.uni-

muenchen.de
OncoTargets and Therapy 2017:10 5179-5186

(c) (7) (을 2017 Tufman et al. This work is published and licensed by Dove Medical Press Limited. The full terms of this license are available at https://www.dovepress.com/terms.php cc. ${ }_{\mathrm{BY}} \mathrm{NC}$ and incorporate the Creative Commons Attribution - Non Commercial (unported, v3.0) License (http://creativecommons.org/licenses/by-nc/3.0/). By accessing the work you hereby accept the Terms. Non-commercial uses of the work are permitted without any further permission from Dove Medical Press Limited, provided the work is properly attributed. For permission for commercial use of this work, please see paragraphs 4.2 and 5 of our Terms (https://www.dovepress.com/terms.php). 
patients over the age of 75 years. ${ }^{3,4}$ In contrast, the average lung cancer patient in Germany is elderly, aged almost 70 years at the time of first diagnosis. ${ }^{5}$

Current guidelines ${ }^{6,7}$ recommend testing all patients with lung adenocarcinoma for EGFR mutation and ALK translocation, regardless of age or other clinical factors and recommend treating patients with these molecular alterations with a first-line EGFR or ALK TKI. However, barriers to universal testing continue to exist in many health care settings, and not all patients who may benefit from TKI therapy are tested for molecular drivers. In particular, use of EGFR and ALK testing appears to be quite low in elderly patients. A recent analysis of 1,358 patients with NSCLC documented in the Surveillance, Epidemiology, and End Results (SEER) Program of the National Cancer Institute database showed a marked inverse correlation between the frequency of EGFR testing and age, with testing in only $13.7 \%$ of adenocarcinoma patients over the age of 80 years, compared with testing in $55.3 \%$ of patients under 50 years, $22.8 \%$ of those aged $50-59$ years and $22.9 \%$ of those aged $60-69$ years. $^{8}$

Because of the good tolerability profile of TKIs, elderly patients - including frail elderly patients who may be poor candidates for chemotherapy - may benefit from treatment with EGFR or ALK TKIs if the relevant molecular drivers are identified. However, there are currently little data as to the rate of EGFR and ALK alterations and response to TKIs in elderly patients with NSCLC.

In this analysis, we sought to describe rates of EGFR mutation and ALK translocation in elderly patients with NSCLC in a tertiary-care university hospital setting in Germany.

\section{Patients and methods}

\section{Study design and objectives}

The primary objective of this retrospective study was to determine the incidence of EGFR mutation and ALK translocation in very elderly patients, defined as those 80 years of age or older at the time of first diagnosis. Secondary objectives included comparing the molecular biology of tumors in very elderly patients with younger seniors aged 70-74 and 75-79 years; describing targeted treatment administered and response to targeted treatment in very elderly patients with NSCLC and examining smoking behavior in very elderly patients. The primary objective was examined in two independent patient cohorts. Approval for this retrospective analysis was obtained from the responsible ethics committee (Ethics Committee of the University of Munich). Due to the retrospective and anonymized nature of the data, individual patient consent was not required (Ethics Committee Decision number 476-16 UE).
The study was conducted according to the Declaration of Helsinki, Good Clinical Practice guidelines and local ethical, legal and confidentiality of data requirements.

\section{Patient cohorts}

The first cohort included all patients with lung cancer over the age of 70 years diagnosed and treated in 2015 at the university hospital affiliated with the Ludwig-Maximilians University of Munich. The university hospital is a member of the Munich Lung Cancer Center. We reviewed the charts and electronic patient records and assessed the frequency and result of EGFR and ALK testing. To confirm the primary finding of the study and to increase the number of patients over the age of 80 years available for exploratory analyses, we then examined a second cohort of octogenarians. For this second cohort, we identified all patients with lung cancer diagnosed in 2014 seen at the university hospital at any time following first diagnosis until October 2016 and reviewed the charts of those over 80 years of age at the time of first diagnosis.

\section{EGFR and ALK testing}

Screening for ALK alterations was performed by immunohistochemistry (clone D5F3, ready-to-use test kit for Ventana platform according to the manufacturer's instructions; Ventana Medical Systems, Inc., Oro Valley, AZ, USA). Positive results of ALK immunohistochemistry were confirmed by fluorescence in situ hybridization (Spec ALK/EML4 TriCheck probe, Zytovision; Zytomed GmbH, Berlin, Germany) with concordant results. Mutational analysis of exons 18-20 of $E G F R$ gene was performed by Sanger sequencing following manual microdissection of tumor areas.

\section{Statistical analysis}

Data sets were anonymized prior to analysis. Statistical analyses were performed using GraphPad QuickCalcs Software. The Chi-square test was applied to compare categorical data. $p$-values were two tailed, and values under 0.05 were considered significant. Linear regression was used to describe the association between age and smoking. Subgroup analyses of elderly patients aged 70-74, 75-79 and $>80$ years in cohort 1 were preplanned. Cohorts 1 and 2 were pooled for an exploratory descriptive analysis of smoking history, treatment with TKI and response to treatment in octogenarians with driver alterations.

\section{Results}

Out of 179 patients diagnosed and treated at our center in 2015 (cohort 1), 16 (8.9\%) were 80 years or older at the time 
of first diagnosis, 26 were $75-79(14.5 \%)$ years of age and $33(18.4 \%)$ were $70-74$ years of age. Of the 16 octogenarians in this cohort, $8(50 \%)$ had non-squamous histology and were tested for EGFR and ALK. Among these very elderly patients, three patients were found to have EML4-ALK translocations and three patients were found to have EGFR mutation (one Del19, one L858R, one rare EGFR mutation in exon 19). This represents a $75 \%$ frequency of treatable driver mutations in octogenarians with non-squamous NSCLC. The frequency of these driver alterations was then assessed in a second cohort of octogenarians. Out of 335 patients diagnosed in 2014 and seen at our center following their diagnosis (cohort 2), $32(9.6 \%)$ were 80 years or older at the time of first diagnosis and $10(31 \%)$ of these octogenarians had non-squamous NSCLC and were tested for EGFR and ALK. One patient was found to have an EML4-ALK translocation, and three patients were found to have an EGFR mutation, representing a $40 \%$ frequency of treatable driver alterations in octogenarians in this cohort; the data are summarized in Table 1.

The incidence of genetic drivers in patients with nonsquamous NSCLC aged 70-74 and 75-79 years in cohort 1 was $27.0 \%$ and $26.7 \%$, respectively. In comparison, the incidence of molecular driver alterations in patients over the age of 80 years was significantly higher, both in cohort $1(p=0.0022)$ and when considering both cohorts together $(p=0.0064)$. A pooled analysis of all patients aged 70-79 years vs those over 80 years confirmed the significantly higher incidence of EGFR/ALK alterations in octogenarians compared with younger seniors aged $70-79$ years $(p=0.039)$.

Interestingly, in each cohort, the single most elderly patient had a treatable driver mutation; in cohort 1 , this was a 91-year-old woman with EML4-ALK translocation and in cohort 2 a 95-year-old woman with EGFR mutation. Among the octogenarians in cohort 1 and cohort 2 , there was a trend toward more advanced age in the subgroup with treatable driver mutations ( 85.3 years in cohort 1 and 86.2 years in cohort 2) than in the subgroup without a treatable driver mutation ( 84 years in cohort 1 and 83.4 years in cohort 2).

\section{Smoking}

An analysis of the smoking history of elderly patients with lung cancer showed that both active smoking and previous smoking was more prevalent in younger seniors than in octogenarians. In the 70-74-year-old subgroup, 30\% were active smokers at the time of first diagnosis and only $9 \%$ had never smoked, whereas only $8 \%$ of octogenarians smoked actively at the time of first diagnosis and 19\% were never smokers. The average pack-years (PY) smoked decreased with increasing subgroup age (Figure 1), with an average of 40.3 PY in 70-74 year olds, 34.3 PY in 75-79 year olds and 27.5 PY in those over the age of 80 years; the data are summarized in Table 2. The majority of octogenarians with driver alterations were never smokers, and the average smoking burden in this group was 4.4 PY (Table 3).

There was a strong trend toward longer survival for octogenarian nonsmokers compared with octogenarian exsmokers/smokers (mean overall survival 21.2 vs 12.2 months; $p=0.0770$ ). We did not find a survival difference between smokers and nonsmokers within either the subgroup with driver alterations or the subgroup with no driver alteration. The overall survival of heavier smokers ( $>50$ PY) did not differ significantly from that of lighter smokers ( $<50$ PY). Approximately $10 \%$ of lung cancer patients aged $70-80$ years

Table I Characteristics of elderly lung cancer patients in cohort I and cohort 2

\begin{tabular}{|c|c|c|c|c|c|}
\hline \multirow[t]{2}{*}{ Characteristics } & \multirow{2}{*}{$\begin{array}{l}\text { Elderly } \\
\text { patients } \\
\text { (>70 years) }\end{array}$} & \multicolumn{3}{|l|}{ Cohort I } & \multirow{2}{*}{$\begin{array}{l}\text { Cohort } 2 \\
\text { Patients } 80 \text { years of } \\
\text { age or older at the } \\
\text { time of first diagnosis }\end{array}$} \\
\hline & & $\begin{array}{l}\text { Patients } 70-74 \text { years } \\
\text { of age at the time } \\
\text { of first diagnosis }\end{array}$ & $\begin{array}{l}\text { Patients } 75-79 \text { years } \\
\text { of age at the time } \\
\text { of first diagnosis }\end{array}$ & $\begin{array}{l}\text { Patients } 80 \text { years of } \\
\text { age or older at the } \\
\text { time of first diagnosis }\end{array}$ & \\
\hline Total, n (\%) & $75(100)$ & $33(44)$ & $26(35)$ & $16(21)$ & $32(100)$ \\
\hline \multicolumn{6}{|l|}{ Gender, n (\%) } \\
\hline Male & $48(64)$ & $18(55)$ & $19(73)$ & II (69) & 14 (44) \\
\hline Female & $27(36)$ & $15(45)$ & $7(27)$ & $5(3 I)$ & $18(56)$ \\
\hline $\begin{array}{l}\text { Mean age at first } \\
\text { diagnosis (years) }\end{array}$ & 76.3 & 71.9 & 76.7 & 84.4 & 82.9 \\
\hline $\begin{array}{l}\text { Patients with non-squamous } \\
\text { NSCLC tested for EGFR } \\
\text { and ALK, } n\end{array}$ & 45 & 22 & 15 & 8 & 10 \\
\hline EGFR positive, n (\%) & $13(29)$ & $6(27)$ & $4(27)$ & $3(38)$ & $3(30)$ \\
\hline ALK positive, n (\%) & $3(6)$ & 0 & 0 & $3(38)$ & I (I0) \\
\hline
\end{tabular}

Abbreviation: NSCLC, non-small cell lung cancer. 


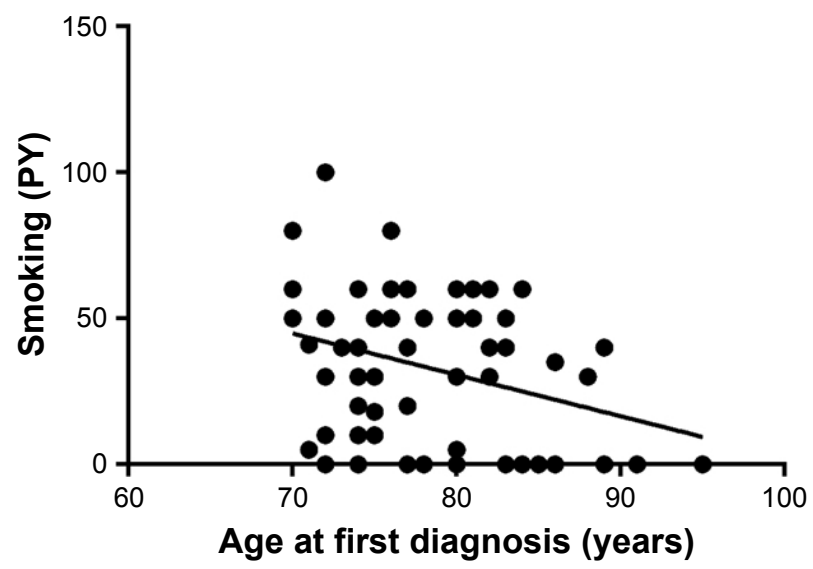

Figure I Smoking history of elderly patients with lung cancer.

Notes: Very elderly patients with lung cancer reported less smoking than did younger seniors with lung cancer. Linear regression was used to describe the association between age and smoking. Slope is $-1.4 \pm 0.55(95 \% \mathrm{Cl}-2.5$ to -0.32 , $p=0.0120$ for nonzero slope).

Abbreviation: PY, pack-years.

were very heavy smokers with over 80 PY smoking history. There were no very heavy smokers ( $>80$ PY) in the octogenarian cohort.

\section{Treatment with TKIs}

In our very elderly subgroup, eight out of the 10 octogenarians with driver alterations were treated with a targeted TKI. The remaining two underwent a surgical resection without systemic therapy. Seven patients received a TKI as first-line treatment, and one patient was initially treated with four cycles of pemetrexed monotherapy before being switched to crizotinib. Seven of eight patients treated with a TKI benefited both clinically and in terms of Response Evaluation Criteria in Solid Tumors response, with an average time to progression of 13.6 months (Figure 2). One patient discontinued crizotinib treatment after 3 weeks and requested a transfer to hospice care. This patient could not be assessed for response. Two patients progressing on EGFR TKIs were found to have T790M mutations and were switched to osimertinib with good treatment effect. Overall survival of octogenarians with driver alterations treated with a TKI was $75 \%$ at 12 months and $57 \%$ at 24 months. Table 3 summarizes the treatments and response of the octogenarian subgroup with driver mutations.

\section{Discussion}

Clinically relevant molecular alterations in NSCLC are believed to be more prevalent in younger patient populations. This study found a clinically relevant incidence of EGFR mutation and ALK translocation in very elderly, octogenarian patients with non-squamous NSCLC. The incidence of driver alterations was higher in very elderly patients than in younger seniors aged 70-79 years. To our knowledge, this is the first study to report on the incidence of these genetic drivers in very elderly patients with lung cancer and is also the first study to compare the incidence of these genetic drivers in very elderly patients ( $>80$ years) to other elderly subgroups. Previous data from a large German cohort of 4,196 adults (average age 66 years) describe EGFR mutations in $10.3 \%$ of patients, with higher incidence in females $(16.7 \%)$, never smokers $(26.2 \%)$ and patients with adenocarcinoma (13.1\%). ${ }^{9}$

At first glance, the finding of a high incidence of molecular driver alterations in octogenarians seems to contradict well-established findings in the biology of lung cancer: EGFR mutation and ALK translocation are generally associated with a set of clinical features including a limited smoking history and younger than average age at the time of tumor diagnosis. The association of these driver alterations with younger patients has been confirmed by many groups,

Table 2 Smoking and histology data for cohort I and cohort 2 (pooled)

\begin{tabular}{|c|c|c|c|c|}
\hline Characteristics & $\begin{array}{l}\text { All elderly } \\
\text { patients } \\
\text { (>70 years) }\end{array}$ & $\begin{array}{l}\text { Patients } 70-74 \text { years } \\
\text { of age at the time } \\
\text { of first diagnosis }\end{array}$ & $\begin{array}{l}\text { Patients } 75-79 \text { years } \\
\text { of age at the time } \\
\text { of first diagnosis }\end{array}$ & $\begin{array}{l}\text { Patients } 80 \text { years of } \\
\text { age or older at the } \\
\text { time of first diagnosis }\end{array}$ \\
\hline Smoking history, $\mathrm{n}$ & 107 & 33 & 26 & 48 \\
\hline Never smoker & 16 & $3(9 \%)$ & $4(15 \%)$ & $9(19 \%)$ \\
\hline Ex-smoker & 41 & $14(42 \%)$ & II (42\%) & $16(33 \%)$ \\
\hline Active smoker & 18 & $10(30 \%)$ & $4(15 \%)$ & $4(8 \%)$ \\
\hline Unknown & 32 & $6(18 \%)$ & $7(27 \%)$ & $19(40 \%)$ \\
\hline Average PY & 32.2 & 40.3 & 34.3 & 27.5 \\
\hline \multicolumn{5}{|l|}{ Histology, n (\%) } \\
\hline Adenocarcinoma & 50 & $19(57)$ & $13(50)$ & $18(38)$ \\
\hline Other non-squamous NSCLC & 9 & $3(9)$ & $3(12)$ & $3(6)$ \\
\hline Squamous cell carcinoma & 29 & $4(12)$ & $8(31)$ & $17(35)$ \\
\hline SCLC & 13 & $6(18)$ & 0 & $7(15)$ \\
\hline Others & 6 & I (3) & $2(8)$ & $3(6)$ \\
\hline
\end{tabular}

Abbreviations: NSCLC, non-small cell lung cancer; PY, pack-years; SCLC, small cell lung cancer. 


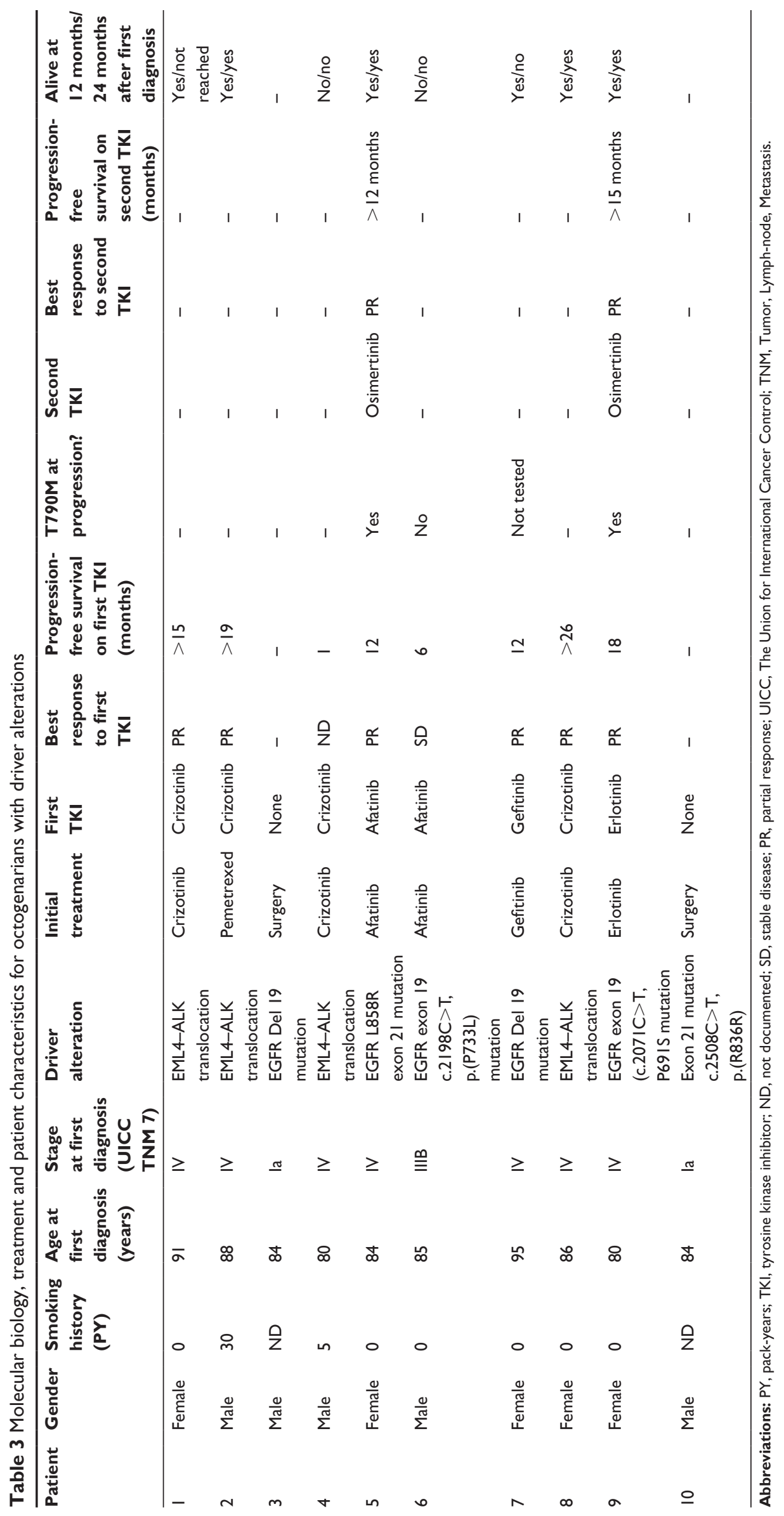




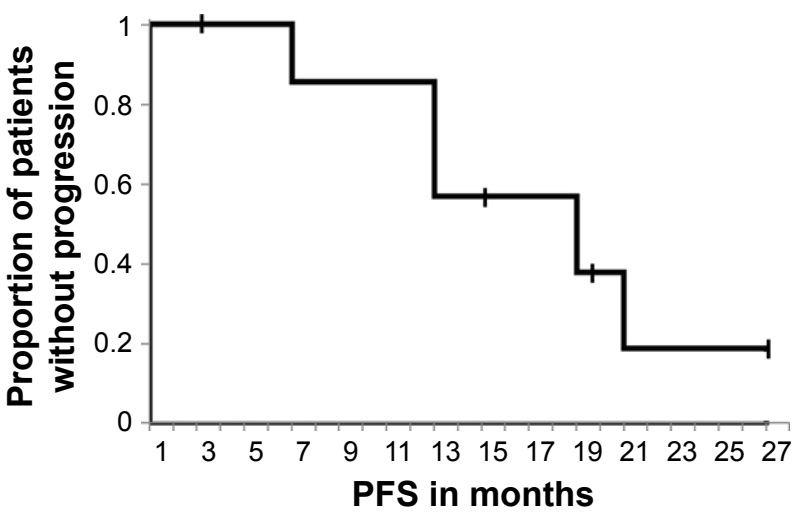

\begin{tabular}{|lllll|}
\hline Nr at risk & 8 & 6 & 4 & 1 \\
\hline
\end{tabular}

Figure 2 PFS of octogenarians treated with an EGFR or ALK TKI. Abbreviations: $\mathrm{Nr}$, number; PFS, progression-free survival; TKI, tyrosine kinase inhibitor.

including our own. ${ }^{10}$ However, when the factors leading to the development of lung cancer and the decreased life expectancy of smokers are considered, the finding of driver mutations in the very elderly does not seem counterintuitive. It could be that those seniors who survive to develop lung cancer at a very advanced age have had relatively little lifelong exposure to carcinogenic tobacco smoke or are resistant to its effects.

Although the incidence of lung cancer increases with increasing age and elderly patients make up the bulk of patients with lung cancer, younger seniors predominate and very elderly patients are a small subgroup. In the current study, fewer than $10 \%$ of lung cancer patients were diagnosed at or over the age of 80 years. Epidemiological data show that, rather than steadily increasing with increasing age, both lung cancer incidence and cancer mortality peak in elderly patients and then decrease in very elderly patient cohorts. ${ }^{11}$ Data from the SEER database describe lower incidence of lung cancer in those 80-84 years of age and $85+$ years than in those aged $75-79$ years. ${ }^{12}$ In addition, an analysis of census data from the USA showed that while $40 \%$ of deaths in those aged 50-69 years were due to cancer, cancer accounted for only $4 \%$ of all deaths in patients over the age of 100 years. ${ }^{13}$ This may be in part due to the decreased life expectancy of smokers, who are less likely to live to the age of 80 years as nonsmokers. ${ }^{14} \mathrm{~A}$ large study including over one million British women found that, compared with only $22 \%$ of never smokers, $53 \%$ of smokers die before reaching 80 years of age. ${ }^{15}$ A study of Italian centenarians showed that $83.8 \%$ of those who reach the age of 100 years have never smoked. ${ }^{16}$ German data on smoking behavior at various ages ${ }^{17}$ show that smoking is most common among young adults aged $18-29$ years, with $40 \%$ of women and $47 \%$ of men smoking daily or on occasion. Heavy smoking (20 or more cigarettes a day) is most common among $30-44$ year olds. ${ }^{17}$ Elderly individuals aged 65-79 years smoke infrequently in Germany ( $8.5 \%$ of men and $16.8 \%$ of women), and only rarely smoke heavily ( $1.5 \%$ of elderly women and $2.4 \%$ of elderly men). ${ }^{17}$ However, in addition to lack of smoking, genetic factors may also play a role in the decreased lung cancer incidence in the very elderly. In a study examining the frequency of chromosomal aberrations in younger and older patients, Erceg et $\mathrm{a}^{18}$ found more aberrations in patients over the age of 65 years than in those under the age of 65 years but fewer chromosomal aberrations in the very elderly (over the age of 80 years) than in younger seniors. There seem to be protective genetic factors present in those who reach extremely old age.

As most investigations to date have considered all elderly patients as a single group, generally defined as over the age of 65 years or over the age of 70 years, rather than further stratifying based on age, differences in the biology of lung cancer in the very elderly may be overlooked. In contrast, geriatricians assessing medical interventions in elderly populations often age stratify their patients as "young old," "middle old" and "old old."19,20 The current study and previous work in other solid tumours ${ }^{21}$ support the use of an age-stratified approach to the biology of cancer in the elderly as tumors which occur in the very elderly appear to differ significantly from those which develop in elderly patients 10 or 20 years younger. There may be at least three biologically relevant age groups in terms of the molecular biology of lung cancer. Lung cancer in the very young seems to arise relatively independent of smoking history and displays a high incidence of molecular driver alterations. Lung cancer incidence is highest in middle age to young/mid-seniors and occurs predominantly in smokers or ex-smokers in these age groups. In the very elderly, lung cancer incidence decreases and a relevant proportion of those cases which do occur appear to be linked to molecular driver alterations. The current study found that octogenarians with lung adenocarcinoma are often never smokers. In addition, despite having had more life years in which to smoke, the average number of PY smoked by very elderly patients with lung cancer was lower than the amount smoked by younger seniors, suggesting that perhaps those who smoke most develop tumors earlier than those who have smoked less.

It is possible that the smoking history of patients seen at our university center is not perfectly representative of the smoking history of all patients with lung cancer in Germany. There may be an unconscious bias among primary care 
physicians to preferentially refer patients to a university center based on factors such as higher socioeconomic status, good clinical condition and limited comorbidity, all of which may be associated with a lower smoking burden. This might lead to an overestimation of mutation prevalence in our study population. In addition to being a predisposing factor for EGFR and ALK wild-type tumor biology, smoking has been previously described as a negative prognostic factor in lung cancer..$^{22}$ In the current study, octogenarian nonsmokers showed a strong trend to longer overall survival compared with former and current smokers; however, the subgroup of octogenarian nonsmokers with wild-type tumor biology was too small to draw conclusions about the independent impact of smoking, tumor biology and treatment on survival.

We are aware of only one other publication examining the rate of EGFR mutations in very elderly patients and no analyses examining ALK in this age group. Nishii et a ${ }^{23}$ previously examined the rate of EGFR mutations in elderly Japanese patients with surgically resected lung cancer and found lower rates of EGFR mutation in those over the age of 80 years compared with younger patients. This group did not compare moderately elderly to very elderly patients. Interestingly, in the Nishii analysis, the rate of smoking in the elderly patient subgroup was significantly higher, at $79.3 \%$, than in the younger subgroup. As both tumor biology and smoking behavior differ between Japanese and German patient cohorts, these data are not directly comparable.

The current study found high rates of response and clinical benefit from TKIs in very elderly patients with molecular driver alterations treated with an appropriate EGFR or ALK TKI. Previous studies have reported that very elderly patients who are biologically fit may tolerate many of the treatment modalities offered to younger patients, including surgical resection and chemotherapy. ${ }^{24}$ However, some very elderly patients with advanced disease decline chemotherapy. ${ }^{25}$ Such patients may benefit from treatment with a TKI if a treatable driver alteration is identified. ${ }^{26}$ The relatively high incidence of driver alterations in very elderly patients identified in the current study is clinically relevant and should motivate clinicians to biopsy and offer molecular testing to patients in this age group. Ayyappan et $\mathrm{a}^{27}$ previously described diagnostic decision making in very elderly patients aged 80 years or older at the time of lung cancer diagnosis. In their cohort from Rochester, New York, $18-23 \%$ of patients were over the age of 80 years at the time of diagnosis, and one-third of these patients declined, either alone or through family members, to have the diagnosis of lung cancer confirmed by a biopsy. The assumption that elderly patients will have low rates of driver mutations may contribute to the relatively low rate of testing for these alterations in very elderly patients in some settings. While some patients may still choose not to undergo a biopsy, very elderly patients should be informed about alternatives to chemotherapy and the possibility of finding molecular drivers before making this decision.

\section{Conclusion}

In this study, very elderly patients with non-squamous NSCLC were found to have relatively high rates of EGFRmutation and ALK-translocation. This finding is both clinically and biologically relevant. Although some physiologically fit elderly patients benefit from chemotherapy, TKIs may also benefit frail or comorbid elderly patients who are not candidates for chemotherapy. As recommended by European ${ }^{6}$ and American ${ }^{7}$ guidelines, testing for these genetic alterations should not be restricted to younger patients. Biologically, the presence of a high rate of driver alterations in patients with lung cancer over the age of 80 years suggests that the biology of lung cancer in various age cohorts and subgroups of elderly patients varies. The biology of tumors in the very elderly may differ from that of tumors in middle-aged patients and younger seniors. Very elderly patients may be less likely to have been heavily exposed to environmental carcinogens such as tobacco smoke or may have genetic factors which lessen the effect of such exposure. Studying the biology of carcinogenesis in very elderly patients may provide insights into factors which predispose to and protect against tumor development.

\section{Acknowledgments}

An abstract describing a portion of these data (preliminary findings) was presented at the World Conference on Lung Cancer in Vienna, Austria, in December 2016 as a poster presentation. The poster's abstract was published in the Journal of Thoracic Oncology (available at www.jto.org/ article/S1556-0864(16)32140-2/pdf).

\section{Disclosure}

The authors report no conflicts of interest in this work.

\section{References}

1. Sequist LV, Yang JC, Yamamoto M, et al. Phase III study of afatinib or cisplatin plus pemetrexed in patients with metastatic lung adenocarcinoma with EGFR mutations. J Clin Oncol. 2013;31(27):3327-3334.

2. Solomon B, Mok T, Kim D-W, et al. First-line crizotinib versus chemotherapy in ALK-positive lung cancer. N Engl J Med. 2014;371(23): 2167-2177. 
3. Mitsudomi T, Morita S, Yatabe Y, et al. Gefitinib versus cisplatin plus docetaxel in patients with non-small-cell lung cancer harbouring mutations of the epidermal growth factor receptor (WJTOG3405): an open label, randomised phase 3 trial. Lancet Oncol. 2010;11(2):121-128.

4. Maemondo M, Inoue A, Kobayashi K, et al. Gefitinib or chemotherapy for non-small-cell lung cancer with mutated EGFR. $N$ Engl J Med. 2010;362(25):2380-2388.

5. Bericht zum Krebsgeschehen in Deutschland 2016 [webpage on the Internet]. Zentrum für Krebsregisterdaten im Robert Koch-Institut (Hrsg). [Cancer in Germany Report]. Berlin: 2016. Available from: http:// www.krebsdaten.de/Krebs/DE/Content/Publikationen/Krebsgeschehen/ Krebsgeschehen_node.html. Accessed January 15, 2017. German.

6. Novello S, Barlesi F, Califano R, et al. Metastatic non-small-cell lung cancer: ESMO clinical practice guidelines. Ann Oncol. 2016; 27(suppl 5):v1-v27.

7. Masters GA, Temin S, Azzoli CG, et al. Systemic therapy for stage IV non-small-cell lung cancer update. JCO. 2015;33(30):3488-3517.

8. Enewold L, Thomas A. Real-world patterns of EGFR testing and treatment with erlotinib for non-small cell lung cancer in the United States. PLoS One. 2016;11(6):e0156728.

9. Schuette W, Schirmacher P, Eberhardt W, et al. EGFR mutation status and first-line treatment in patients with stage III/IV non-small-cell lung cancer in Germany: an observational study. Cancer Epidemiol Biomark Prev. 2015;24(8):1254-1261.

10. Tufman AL, Edelmann M, Gamarra F, et al. Preselection based on clinical characteristics in German non-small-cell lung cancer patients screened for EML4-ALK translocation. J Thorac Oncol. 2014;9(1): 109-113.

11. Driver JA, Djoussé L, Logroscino G, Gaziano JM, Kurth T. Incidence of cardiovascular disease and cancer in advanced age: prospective cohort study. BMJ. 2008;337:a2467.

12. Howlader N, Noone A, Krapcho M, et al. [webpage on the Internet]. Previous Version: SEER Cancer Statistics Review, 1975-2013. Bethesda, MD: National Cancer Institute. Available from: http://seer.cancer.gov/ csr/1975_2013/. Accessed August 30, 2017. [Based on November 2015 SEER data submission, posted to the SEER web site, April 2016].

13. Smith DWE. Cancer mortality at very old ages. Cancer. 1996;77(7): 1367-1372.

14. CDC [webpage on the Internet]. Tobacco-Related Mortality. Available from: https://www.cdc.gov/tobacco/data_statistics/fact_sheets/ health_effects/tobacco_related_mortality/. Accessed January 15, 2017.

15. Pirie K, Peto R, Reeves G, Green J, Beral V; Million Women Study Collaborators. The 21 st century hazards of smoking and benefits of stopping: a prospective study of one million women in the UK. Lancet. 2013;381(9861):133-141.
16. Tafaro L, Cicconetti P, Tedeschi G, et al. Smoking and longevity: an incompatible binomial? Arch Gerontol Geriatr Suppl. 2004;9: 425-430.

17. Lampert T, von der Lippe E, Müters S. Prevalence of smoking in the adult population of Germany. Results of the German Health Interview and Examination Survey for Adults (DEGS1). Bundesgesundheitsbl. 2013;56:802-808

18. Erceg P, Milosevic DP, Despotovic N. Chromosomal changes in ageing. J Genet. 2007;86(3):277-278.

19. Forman DE, Berman AD, McCabe GH, et al. PTCA in the elderly: the "young-old" versus the "old-old". J Am Geriatr Soc. 1992;40(1):19-22.

20. Lyketsos CG, Weiller E, Katona C, Gorwood P. Are old-old patients with major depression more likely to relapse than young-old patients during continuation treatment with escitalopram? BMC Geriatr. 2011;11:2.

21. Azim HA, Nguyen B, Brohée $S$, et al. Genomic aberrations in young and elderly breast cancer patients. BMC Med. 2015;13:266.

22. Janjigian Y, McDonnell K, Kris M, et al. Pack years of cigarette smoking as a prognostic factor in patients with stage IIIB/IV non-small cell lung cancer. Cancer. 2010;116(3):670-675.

23. Nishii T, Yokose T, Miyage Y, et al. Clinicopathological features and EGFR gene mutation status in elderly patients with resected non-small cell lung cancer. BMC Cancer. 2014;14:610.

24. Blanchard EM, Arnaoutakis K, Hesketh PJ. Lung cancer in octogenarians. J Thorac Oncol. 2010;5(6):909-916.

25. Oxnard GR, Fidias P, Muzikansky A, Sequist LV. Non-small cell lung cancer in octogenarians: treatment practices and preferences. $J$ Thorac Oncol. 2007;2(11):1029-1035.

26. Chen KY, Chen JH, Shih JY, Yang CH, Yu CJ, Yang PC. Octogenarians with advanced non-small cell lung cancer: treatment modalities, survival, and prognostic factors. J Thorac Oncol. 2010;5(1):82-89.

27. Ayyappan S, Gonzalez C, Yarlagadda R, Zakharia Y, Woodlock TJ. Lung cancer in the very elderly: incidence, presentation, and diagnostic decision-making. A retrospective analysis at a teaching community hospital. J Community Hosp Intern Med Perspect. 2011;1(3):1-6.

28. Sacher AG, Dahlberg SE, Heng J, et al. Association between younger age and targetable genomic alterations and prognosis in non-small-cell lung cancer. JAMA Oncol. 2016;2(3):313-320.

29. Pao W, Miller V, Zakowski M, et al. EGF receptor gene mutations are common in lung cancers from "never smokers" and are associated with sensitivity of tumors to gefitinib and erlotinib. Proc Natl Acad Sci USA. 2004;101(36):13306-13311.
OncoTargets and Therapy

\section{Publish your work in this journal}

OncoTargets and Therapy is an international, peer-reviewed, open access journal focusing on the pathological basis of all cancers, potential targets for therapy and treatment protocols employed to improve the management of cancer patients. The journal also focuses on the impact of management programs and new therapeutic agents and protocols on

\section{Dovepress}

patient perspectives such as quality of life, adherence and satisfaction The manuscript management system is completely online and includes a very quick and fair peer-review system, which is all easy to use. Visit http://www.dovepress.com/testimonials.php to read real quotes from published authors. 